\title{
Pesquisa ação e possibilidades de interculturalidade crítica e decolonização da prática acadêmica: comunidade Kanhgág (Kaingang) Por Fi Ga /RS/Brasil ${ }^{1}$
}

\begin{abstract}
Resumo
Este trabalho traz relatos de experiência sobre as possibilidades de decolonialidade acadêmica advindas de pesquisas universitárias, desde que, sob perspectivas interculturais críticas, que questionem as estruturas vigentes. Entende-se a decolonialidade acadêmica como processos em que a Universidade e suas instâncias podem auxiliar e legitimar as ações e formações comunitárias autônomas, divergindo da maneira usual como são estabelecidas as questões indígenas no interior das Universidades, geralmente sem a participação das comunidades, como objetos de estudo ou participantes esporádicos de eventos não remunerados. A partir do método da Pesquisa Ação, selecionamos uma demanda comunitária a ser resolvida pela pesquisa que resultou em Dissertação de Ciências Sociais. Como resultados deste estudo, coloca-se que é fato que, desde a promulgação de leis que obrigam as instituições a ministrarem em seus cursos temáticas que reflitam as versões indígenas sobre a história do país (Lei 11.645/08), tem havido um crescimento na visibilidade desses agentes e seus temas. Porém, são ações ainda teóricas ou com práticas isoladas, de professores e alunos, sem a participação efetiva da comunidade Por Fi Ga, configurando assim, uma interculturalidade funcional, conveniente ao Estado, que somente "encaixa" os agentes e temas em uma estrutura desigual já vigente. Acredita-se que os potenciais decoloniais da academia, residem na relação de respeito e reciprocidade entre seus funcionários, as pesquisas e a localidade, nesse caso, a comunidade Kanhgág Por Fi Ga. É preciso que a academia se abra a aprender outras epistemologias, construindo espaços que realmente funcionem a partir da própria comunidade, valorizando o conhecimento a partir dos moradores.
\end{abstract}

Palavras-chave: Pesquisa ação. Interculturalidades. Decolonialidade. Kanhgág. Kaingang.

\section{Para citar este artigo:}

DAMASCENO, Maira. Pesquisa ação e possibilidades de interculturalidade crítica e decolonização da prática acadêmica: comunidade Kanhgág (Kaingang) Por Fi Ga /RS/Brasil. PerCursos, Florianópolis, v. 22, n.48, p. 284 - 318, jan./abr. 2021.

DOI: $10.5965 / 1984724622482021284$

http://dx.doi.org/10.5965/1984724622482021284

\footnotetext{
${ }^{1}$ O presente trabalho foi realizado com apoio da Coordenação de Aperfeiçoamento de Pessoal de Nível Superior - Brasil (CAPES) - Código de Financiamento 001.
}

\author{
Maira Damasceno \\ Doutoranda em Estudos \\ Históricos Latino-Americanos \\ pela Universidade do Vale do \\ Rio dos Sinos - Unisinos. \\ Brasil \\ dms.maira@gmail.com
}




\title{
Action research and possibilities of critical interculturality and decolonization of academic practice: Kanhgág (Kaingang) community Por Fi Ga /RS/ Brasil $^{2}$
}

\begin{abstract}
This study brings experience reports on the possibilities of academic decoloniality coming from university research, provided that, under critical intercultural perspectives, they question the current structures. Academic decoloniality is understood as processes in which the University and its instances can assist and legitimize autonomous community actions and formations, diverging from the usual way in which indigenous issues are established inside Universities, usually without the communities' participation, as objects of study or sporadic participants in unpaid events. Using the Action Research method, we selected a community demand to be solved by research that resulted in a Social Science Thesis. As a result of this study, it is a fact that, since the enactment of laws that oblige institutions to teach in their programs topics that reflect indigenous versions on the country's history (Law 11.645/08), there has been an increase in the visibility of these agents and their topics. However, these are still theoretical actions or isolated practices, carried out by teachers and students, without the effective participation of the Por Fi Ga community, thus configuring a functional interculturality, convenient to the State, which only "fits" the agents and themes into an unequal structure already in place. We believe that the academy's decolonial potentials lie in the respectful and reciprocal relationship among its employees, the research, and the locality, in this case, the Kanhgág Por Fi Ga community. The academy needs to open itself to learning other epistemologies, building spaces that really work from within the community itself, valuing
\end{abstract}

\footnotetext{
2 This study was financed in part by the Coordenação de Aperfeiçoamento de Pessoal de Nível Superior Brasil (CAPES) - Finance Code 001.
} 
knowledge starting from the residents.

Keywords: Action research. Interculturalities.

Decoloniality. Kanhgág. Kaingang.

\section{Introdução}

Este trabalho foi construído em conjunto com a comunidade 3 Kanhgág4 Por Fi Ga do Estado do Rio Grande do Sul, Brasil, entre os anos de 2016 e 2108, sendo apresentado em Dissertação no Programa de Pós-Graduação em Ciências Sociais e aqui revisado.

A partir de aportes interculturais críticos e decoloniais, os objetivos principais foram a valorização da autonomia Kanhgág e da prática de pesquisa em conjunto da comunidade Por Fi Ga de forma a adotar algumas demandas comunitárias locais possíveis, através da investigação acadêmica. Para isso, foi utilizado o método da pesquisa ação, que pode ser descrita como o agir em conjunto, de forma organizada com responsabilidade social para a resolução prática de alguma questão colocada por um coletivo. Nesse sentido:

A pesquisa-ação surgiu da necessidade de superar a lacuna entre teoria e prática. Uma das características deste tipo de pesquisa é que através dela se procura intervir na prática de modo inovador já no decorrer do próprio processo de pesquisa e não apenas como possível consequência de uma recomendação na etapa final do projeto. (ENGEL, 2000, p. 182)

Ao refletir sobre as práticas de pesquisa, realizadas em comunidades indígenas, e a responsabilidade do pesquisador perante as pessoas, direta ou indiretamente, implicadas em seus trabalhos, surgem, assim como nos diz Engel (2000), lacunas acadêmicas entre os

\footnotetext{
${ }^{3}$ A noção de comunidade, utilizada neste trabalho, sinaliza a diferença entre a comunidade Kanhgág Por Fi Ga e a "comunidade nacional" (MONEBHURRUN, et al., 2016, p. 445), dos "não Kanhgág" (fóg) fora da Por Fi Ga. É um termo jurídico do direito internacional, de identificação comum; de quem pertence a um grupo; quem é reconhecido como participante de tal grupo; comunidade. Uma diferenciação entre o ser Kanhgág e pertencer à comunidade Por Fi Ga, não outra.

4 Este termo é a autodenominação étnica e foi emprestado do Trabalho de Conclusão de Curso em Pedagogia de Dorvalino Refej Cardoso (2014). Serão utilizadas outras palavras em idioma Kanhgág, sempre sinalizadas.
} 
discursos e as práticas, quando não muito, nesse meio, a ação seja desvalorizada e até mesmo vista como uma vulnerabilidade do pesquisador ou depreciada como forma de ciência. A pretensa neutralidade de pesquisa e busca por objetividade através da distância com o "objeto" de estudo são assuntos superados, pois, se sabe que todo pesquisador carrega consigo suas próprias referências de vida, possui sua subjetividade e fará escolhas baseadas em suas experiências; desse modo, não há espaço para uma ação neutra e livre de escolhas. A ciência brasileira fundou-se a partir de posicionamentos abertamente eurocêntricos, sendo responsável por inúmeras concepções e diferenciações perpetuadas em diversos enquadramentos, estruturas e instituições país afora. Segundo Jessé Souza,

É preciso sempre levar em conta que, na sociedade contemporânea, a legitimação da dominação social é realizada pela "ciência" de modo semelhante à maneira como as grandes religiões do passado faziam nas sociedades tradicionais. São sempre ideias de intelectuais e especialistas que estão na base de programas de partido político, de planejamento do Estado, do que se ensina em salas de aula, do que se decide em tribunais e daquilo que se publica em jornais. (SOUZA, 2015, p. 6)

A ciência, portanto, tem um papel muito importante na disseminação e legitimação de ideias e ações. A pesquisa ação em conjunto dos aportes do pensamento decolonial possibilitam outras perspectivas que foram desconsideradas pela colonialidade, auxiliando para a pluralidade e contraditório das narrativas, contribuindo, principalmente, para o não engessamento ou naturalização de ideias e noções hierarquizantes, por exemplo.

Esse tipo de pesquisa envolve diversas etapas de compromisso e reconhecimento das problemáticas junto da comunidade escolhida. Nesse caso, a pesquisa ação ocorreu junto da comunidade Kanhgág Por Fi Ga em São Leopoldo devido, não só aos nossos objetivos iniciais (pesquisa e comunidade) terem se encontrado, mas também ao comprometimento e responsabilidade social perante os processos históricos e realidades desiguais, resultantes desses. A academia, nesse sentido, pode envolver-se mais, 
pensando também no fato dessa comunidade ficar a uma distância de oito quilômetros da universidade e não ser favorecida com nenhum tipo de apoio ou representação dentro da instituição. A ciência não só pode, como deve intervir de forma que contribua com a solução, em conjunto, de algum problema relevante para as comunidades, e não somente para os pesquisadores ou universidades, como fonte de curiosidades ou de títulos acadêmicos. Se não há reciprocidade e diálogo, acabam formando-se "falsos problemas" (RAMOS, 1974), em relação às diversas realidades vividas e sentidas.

A Universidade como instituição educacional com ênfase social, tem todas as ferramentas disponíveis para interferir positivamente nas demandas dessas comunidades, manter um duradouro diálogo de reciprocidades e ainda contribuir para a formação e relação de seus alunos com as realidades latino-americanas, desde que, sob perspectivas críticas de interculturalidade decolonial, algo ainda distante das universidades brasileiras.

Tem-se visto alguns avanços, porém, ainda teóricos e com práticas isoladas. As teorizações devem ser valorizadas, mas necessitam estar em conjunto com métodos que considerem as demandas, realidades, filosofias e, principalmente, autonomias dos sujeitos envolvidos.

\section{Colonialidade do saber e as Universidades no Brasil}

As universidades brasileiras são ocidentalizadas, e este modelo, segundo Ramon Grosfoguel (2016), privilegia o ensino de pontos de vista nortistas e eurocêntricos desconsiderando ou relativizando outras epistemologias. A universalização dessas narrativas locais do Norte, causaram e ainda causam, através da colonialidade do saber, (QUIJANO, 1997, 2005) a marginalização e a invisibilidade de diversas populações do Sul global e de seus saberes, como dos povos nativos da América e África que tiveram suas epistemologias relegadas à exclusão das bases científicas monopolizadas pelo Norte global.

Enrique Dussel (2005) expõe as falácias modernistas da "história mundial" estabelecidas pelo eurocentrismo. A cronologia, imposta pelos estudos históricos, 
chamada "linha do tempo", prioriza os acontecimentos do Norte global e é, ainda, utilizada como base de diversos estudos pelo Sul global. Porém, em cada parte do mundo, os tempos e processos são diferenciados devido à diversidade de ambientes, formas de interação e cosmologias existentes “[...] não há uma história mundial - mas histórias justapostas e isoladas: a romana, persa, dos reinos hindus, de Sião, da China, do mundo mesoamericano ou inca na América, etc." (DUSSEL, 2005, p. 26). Os processos históricos investigados de maneira "mundial" têm bases evolucionistas e não ultrapassam as construções e representações de uns grupos sobre outros. Acabam por invisibilizar e marginalizar epistemologias, além de alienar os processos de identidade dos grupos historicamente subalternizados.

Dussel (2005) propõe a reconceituação do termo “Europa” a partir da contextualização das narrativas históricas para além dos discursos eurocêntricos. Segundo o autor, a Europa moderna é o resultado de uma invenção ideológica do final do século XVIII. Até então, a “Europa” é que ocupava o lugar do "bárbaro", pois não fazia parte da Grécia original e, nessa época, a referência para o “ocidental” seria o Império Romano que tinha o latim como língua oficial. Ocidental, justamente para diferenciar-se do "oriental" helenista que tinha o grego como língua oficializada. Nesse sentido, o autor demonstra que as influências da Europa Moderna não se cruzam nem com Grécia, nem com Bizantinos (Império Romano do Oriente) “[...] mas sim com todo o mundo latino romano ocidental cristianizado" (2005, p. 25).

O protagonismo do mundo oriental, particularmente o muçulmano a partir do século VII, é enfatizado. Pela primeira vez há distinção entre: Europa Latina, África Muçulmana e Bizantinos. A tentativa inicial de a Europa se impor foi através das Cruzadas (Primeira no ano de 1095), porém “Fracassam, e com isso a Europa latina continua sendo uma cultura periférica, secundária e isolada pelo mundo turco muçulmano [...]" (DUSSEL, 2005, p. 25).

Desse modo, Dussel (2005) defende que a “modernidade" europeia teve início no ano de 1492, com a invasão da América e o início de um sistema, só naquele momento, global, sendo esse o fato crucial para que a Europa conseguisse forçar sua "centralidade" histórica: 
A Espanha, como primeira nação 'moderna' [...] abre a primeira etapa 'Moderna': o mercantilismo mundial. As minas de prata de Potosi e Zacatecas (descobertas em 1545-1546) permitem o acúmulo de riqueza monetária suficiente para vencer os turcos [...]. Para nós, a 'centralidade' da Europa Latina na História Mundial é o determinante fundamental da Modernidade. Os demais determinantes vão ocorrendo em torno dele (a subjetividade constituinte, a propriedade privada, a liberdade contratual, etc.) são o resultado de um século e meio de 'Modernidade': são efeito, e não ponto de partida [...]. A segunda etapa da 'Modernidade' a da Revolução Industrial do século XVIII e da llustração, aprofundam e ampliam o horizonte cujo início está no século XV. A Inglaterra substitui a Espanha como potência hegemônica até 1945 [...] Esta Europa Moderna, desde 1492, 'centro' da História Mundial, constitui, pela primeira vez na história, a todas as outras culturas como sua 'periferia'. (DUSSEL, 2005, p. 27)

Para o autor, devemos combater o mito de que "A modernidade é uma emancipação, uma 'saída' da imaturidade por um esforço da razão como processo crítico, que proporciona à humanidade um novo desenvolvimento do ser humano" (2005, p. 27). Portanto, para superarmos essa modernidade, Dussel propõe o termo "Transmodernidade" que seria a modernidade agora reconhecendo a alteridade antes recusada, “[...] a razão moderna é transcendida (mas não como negação da razão enquanto tal, e sim da razão eurocêntrica, violenta, desenvolvimentista, hegemônica)" (2005, p. 29).

Segundo Ramón Grosgoguel (2016), as Universidades, de forma geral, seguem traçados ocidentalizados. São enraizadas no discurso da modernidade emancipadora e do humanismo seletivo e, desse modo, tendem a epistemicídios e interculturalidades funcionais (WALSH, 2012, p. 65) ao Estado, ou seja, cumprindo as leis, porém, não questionando as hierarquias do conhecimento, nem agregando outras epistemologias em seus quadros. Assim, para Grosgoguel (2016), a transmodernidade, aplicada à educação, substituiria a Universidade pela Pluriversidade, ou seja, em vez de poucos definindo por muitos sobre a validade e legitimação do conhecimento, seriam muitos decidindo por 
muitos, de maneira que os "outros" conhecimentos não sejam vistos como "subalternos" e sim, que sejam reconhecidos.

\subsection{Ocidentalização epistêmica do “outro” e a curiosidade acadêmica}

A colonialidade do saber, segundo Aníbal Quijano (1997, 2005) é o legado epistêmico do colonialismo, ou seja, são epistemes e noções eurocêntricas locais que foram universalizadas e legitimadas como válidas em preterimento de outras noções. Desse modo, as "outras" epistemes foram consideradas pela ciência hegemônica como “subalternas" e, a partir daí, estudadas. Nesse sentido, os estudos sobre as “identidades” são predominantes. Ao longo dos tempos, diversas perspectivas foram criadas, transformadas e superadas para falar e entender sobre as "outras epistemologias", geralmente, pertencentes a povos nativos que tiveram seus territórios invadidos e saqueados pelo colonialismo europeu.

Para a antropologia, o estudo “do outro", até os anos de 1960, era realizado com concepções evolucionistas e estruturalistas, isto é, as identidades faziam parte de uma hierarquia, na qual o homem europeu ocupava o grau máximo de desenvolvimento cultural devendo ser "copiado" pelos ditos "povos primitivos", objetos de estudo da antropologia. Essa disciplina, por ter se desenvolvido em meios europeus, justamente para estudar "o diferente", é responsável por diversas "definições” do que seria esse “outro”, porém, sempre através de conceitos e percepções europeias. O ser indígena talvez tenha sido o maior alvo de tentativas de definição por parte da antropologia. Tentativas essas, sempre fracassadas, pois além da imensa diversidade dos inúmeros e heterogêneos grupos que se tentava enquadrar em uma categoria única e colonial chamada "índios", a identidade é mais do que algo que podemos catalogar como um “modelo" fixo ou meramente biológico.

Essa categoria colonial (os índios) foi aplicada indiscriminadamente a toda a população nativa, sem levar em consideração as profundas diferenças que separavam os distintos povos e sem fazer concessões às identidades preexistentes. Assim, todos os povos aborígenes foram equiparados, porque o que conta é a relação de domínio colonial 
em que só cabem dois polos antagônicos, excludentes e necessários: o dominador e o dominado, o superior e o inferior, a verdade e o erro (BONFIL-BATALLA, 1972, p. 109). A partir dessa definição dicotômica entre o ser "índio" e o "não ser índio", a antropologia do Norte os fez de objeto. Conforme a passagem do tempo se deu, foi enquadrado como exótico, hostil, selvagem, incivilizado, irracional, fixo no tempo, passível de preservação, de assimilação, aculturado. O “outro”, o índio.

A partir das perspectivas pós-coloniais e decoloniais dos anos de 1960 e 1970, a ciência antropológica compreende novas perspectivas que fazem protagonistas as antropologias do Sul, que não querem mais a reprodução dos conhecimentos do Norte, mas sim uma análise a partir da sua realidade.

Se para qualquer observador, incluindo o superficial, é óbvia a semelhança social e cultural dos países latino americanos entre si e evidente a diferença de sua "matriz cultural comum" dos países originários da antropologia e se a acima mencionada vinculação ciênciasociedade é significativa, então é de se esperar a existência de uma espécie de "cultura antropológica" típica e própria das Antropologias do Sul latino-americanas. (KROTZ, 2006, p. 12)

A ideia, segundo Esteban Krotz, não é confrontar a comunidade antropológica internacional, mas, reconhecer os diversos perfis no centro das ciências especializadas nos fenômenos da diversidade "[...] e contribuir, portanto, no sul e desde o sul a um melhor conhecimento da antropologia como conhecimento cognitivo e, por conseguinte, ao melhoramento do conhecimento antropológico no sul e em nível mundial, de que o sul faz parte." (2006, p. 13). A busca por autonomia e protagonismo, teórico e prático, é mais do que um fato latino-americano, é uma necessidade de pensarmos as nossas próprias realidades e processos de identidade através dos nossos processos históricos.

Segundo Tomáz Tadeu da Silva:

Fixar uma determinada identidade como a norma é uma das formas privilegiadas de hierarquização das identidades e das diferenças. A normalização é um dos processos mais sutis pelos quais o poder se manifesta no campo da identidade e diferença. Normalizar significa eleger - arbitrariamente - uma identidade específica como o parâmetro 
em relação ao qual as outras identidades são avaliadas e hierarquizadas. Normalizar significa atribuir a essa identidade todas as características positivas possíveis, em relação às quais as outras identidades só podem ser avaliadas de forma negativa. A identidade 'normal' é natural, desejável, única. (SILVA, 2012, p. 83)

O contexto normativo branqueador ${ }^{5}$ do processo histórico brasileiro não pode ser desconsiderado ao falarmos de processos de identidade, principalmente de indígenas e afrodescendentes que foram desqualificados e marginalizados por esse contexto.

\begin{abstract}
O Brasil, ao contrário constituiu-se negando as suas diferenças. Originário de matriz cultural tríplice apoiada e alimentada em três grandes tradições, com raízes distintas - a indígena, a africana ou dos afrodescendentes e a europeia ou branca - o Brasil alienou-se desta sua própria origem mediante um trágico processo de branqueamento e de enquadramento euro-referente de sua memória. Este foi o modelo colonial. O processo colonial vivido não tinha outro horizonte possível em sua cosmovisão. O Brasil teve assim o seu processo histórico enquadrado desde o início dentro do modelo colonial europeu e português. A sua memória veio sendo enquadrada. (FOLLMANN, et al., 2017, p. 40)
\end{abstract}

Segundo Michael Pollack (1992), o “enquadramento da memória” pode ser realizado de maneira individual ou coletiva à medida que a memória é herdada, selecionada, construída e variada. No caso do Brasil, e especialmente da cidade de São Leopoldo, esse enquadramento representa uma grande alienação quanto às narrativas dos processos históricos. "Somos produtos da alienação. Somos fruto de processos perversos de branqueamento, ou seja, de políticas afirmativas da cultura branca como nossa normatividade" (FOLLMANN et al., 2017, p. 41). No Brasil, as populações marginalizadas sempre foram alvo de subjetivações que identificavam "o outro" através de idealizações fora de contexto:

5 Como "branquear" entendemos a atitude e ideias coloniais. Não se trata simplesmente do branqueamento da cor da pele, mas fundamentalmente o branqueamento das ideias e mentes que criam diferenciações entre os seres humanos. 
Conforme Michele Bertrand se a fonte de 'identidade' é subjetiva, o resultado é um sujeito 'clivado', isto é, dividido entre seu valor social e o socialmente reconhecido. (BERTRAND, 1996 apud DAMASCENO, 2017, p. 8)

Assim, o desejo de reunificação com certa origem, causa ilusões. Nesse caso, dos não índios sobre os índios, pois aos índios sempre são exigidos certos essencialismos que dividem os imaginários a respeito dos sujeitos reais e virtuais. (DAMASCENO, 2017, p. 8)

Nesse sentido, os enquadramentos colonialistas até hoje vigentes que qualificam, diferenciam e essencializam os povos, interferem diretamente nos seus processos de identidade à medida que fixam, idealizam e cobram certas atitudes dos sujeitos.

O que é ser "índio"? Cada povo é único e deve ser reconhecido e valorizado como tal. Para os jovens Kanhgág, ser Kanhgág é o cotidiano e a materialidade, não pode ser medido. Assim, o exótico está nos olhos de quem quer enxergá-lo, fixo, e não a realidade de lutas. Segundo o Professor Dorvalino Refej, “A gente dança quando tem motivo, a gente pinta quando tem motivo, não é todo dia e qualquer hora" ${ }^{6}$. Os momentos são particulares, devem ser respeitados, compreendidos e não banalizados e transformados em alegorias pelos fóg.

\subsection{Colonialidade e Interculturalidade relacional/funcional}

A colonialidade está diretamente ligada às ações interculturais relacionais e/ou funcionais, pois, não conseguem ultrapassar as hierarquias epistemológicas naturalizadas pelo eurocentrismo:

Conforme Catherine Walsh (2012) há três tipos de interculturalidade: relacional, funcional e crítica. $\mathrm{Na}$ 'relacional', há contato e intercâmbio entre práticas, saberes e valores, porém a situação de dominação está presente e não sofre ameaças. Nessa perspectiva inviabiliza-se e minimizam-se os conflitos estruturais presentes nas sociedades. A perspectiva 'funcional' reconhece as diversidades e às pretende incluir ao modelo vigente, tornando-as úteis ao sistema. Como não questiona as

\footnotetext{
${ }^{6}$ Informação Verbal do professor Dorvalino Refej Cardoso, em 29 de março de 2018, na Comunidade Por Fi Ga.
} 
estruturas, nem propõe uma sociedade mais igualitária, torna-se mais uma estratégia de dominação, no sentido da inclusão nesse caso, representar a reprodução do sistema diferenciador. Na terceira perspectiva, chamada 'crítica', o ponto de início é o problema da estrutura colonial, portanto questiona o sistema vigente e seu padrão de diferenciação '[...] o problema central de que parte a interculturalidade não é a diversidade étnico cultural, é a diferença construída como padrão de poder colonial que segue transcendendo praticamente todas as esferas da vida. (DAMASCENO, 2018, p. 05-06)

O sul do Brasil, contexto deste trabalho, possui um imaginário identitário ligado ao eurocentrismo derivado das imigrações predominantemente germânicas e italianas. Esse imaginário construiu narrativas épicas de pontos de vista exclusivamente eurocêntricos e dicotômicos em que o imigrante é o grande herói que luta contra as adversidades, sejam naturezas ou índios selvagens, mas, com muito trabalho criam e desenvolvem as cidades. As trajetórias e realidades de negros e índios, nesse contexto, são pouco consideradas na grande maioria dos municípios sul rio grandenses. E não estamos falando de mera inclusão em espaços museais ou midiáticos, pois essa é uma falsa compreensão do que seria o sentido da história para os Kanhgág.

Uma dessas cidades é São Leopoldo. Distante $28 \mathrm{~km}$ de Porto Alegre, capital do Estado do Rio Grande do Sul, extremo sul do Brasil, em 2010 possuía duzentos mil habitantes, sendo $14 \%$ autodeclarados pretos e pardos e a décima maior comunidade indígena em área urbana do Estado7. Com aproximadamente 500 moradores no ano de 2020, a comunidade Kanhgág Por Fi Ga, desde o final do ano de 2007, está localizada na “Estrada do Quilombo", situada no primeiro bairro da cidade, “Feitoria”, devido ao empreendimento português "Real Feitoria do Linho Cânhamo", instalado nessa região no ano de 1788 para a produção de cordas e tecidos a partir da fibra das plantas de Cânhamo, espécie de Cannabis com baixo teor de princípio ativo. Época essa que precede a chegada dos imigrantes alemães em 1824, porém pouco valorizada nas narrativas

\footnotetext{
7 Censo 2010 IBGE "Municípios com as maiores populações indígenas do País, por situação do domicílio População absoluta" Rio Grande do Sul. Disponível em: https://indigenas.ibge.gov.br/graficos-e-tabelas2.html. Acesso em: 01 mar. 2021

${ }^{8}$ Em 1822 mudou o nome para "Imperial Feitoria do Linho Cânhamo" sendo desativada definitivamente em 1824 e suas construções utilizadas para abrigar os colonos germânicos. Mais sobre a empresa Feitoria em: (ROSA, 2019)
} 
oficiais do município que é considerado por Lei o "Berço da Colonização alemã no Brasil"9.

A imigração germânica tem a seu favor discursos que foram construídos historicamente para elevar o status e a epistemologia do imigrante, diminuindo e invisibilizando as outras. Essas narrativas positivadas, instaladas por gerações de descendentes da imigração e estudiosos das próprias famílias, atualmente se refinaram. Por todo o Estado do Rio Grande do Sul há a presença de discursos civilizatórios em históricos de cidades divulgados pelas prefeituras, museus regionais e núcleos de estudos dedicados à transmissão das estórias, elevação de status e memória dos imigrantes.

É possível pontuar que, a partir do advento das Leis de incentivo às ações afirmativas e da obrigatoriedade do ensino e referências afro e indígenas nas escolas e Universidades, é percebida a presença dessas referências nesses espaços, porém, sem questionar o discurso épico já naturalizado, apenas encaixando as temáticas de forma rasa, configurando ações de interculturalidade relacional e/ou funcional (WALSH, 2012), sem compartilhamentos horizontais de espaço, nem reconhecimentos e participações na construção de políticas públicas próprias. O mesmo apoio, inclusive financeiro, que a prefeitura municipal concede aos projetos culturais germânicos, deveria ser concedido à comunidade Kanhgág para sua própria divulgação. Porém, o município faz uma escolha das narrativas priorizadas, e essas, giram em torno da imigração germânica e seus supostos esforços para o desenvolvimento do município: “[...] com o intuito de povoar e desenvolver a região o Governo Imperial do Brasil estimulou a vinda de imigrantes alemães para o Sul do país [...] (SÃO LEOPOLDO, 2021).

A narrativa do desenvolvimento econômico e cultural do município, conseguido através dos esforços germânicos é corriqueira e naturalizada, elevando o imigrante e implicitamente desvalorizando outras matrizes culturais, “[...] lançando progresso através da dedicação ao trabalho e a diversificação produtiva, tendo em vista que os alemães dominam diversas técnicas de várias profissões." Quem também dominava várias técnicas de várias profissões, nessa mesma época, eram os escravizados que os

\footnotetext{
${ }^{9}$ Lei Federal n 12.394, de 4 de março de 2011.
} 
germânicos compravam para executarem suas tarefas e outras tantas, mas, que no entanto, não são lembrados pela prefeitura, evidenciando, assim, essa preferência pelos sentidos germânicos da história.

Sobre o feriado municipal, no “dia do imigrante”, a prefeitura diz o seguinte: “[...] mo município busca resgatar a memória e a variada contribuição dos alemães para o progresso e desenvolvimento de nosso município, de nossa região e do estado" (SÃO LEOPOLDO, 2021). Todas as três últimas citações saíram de um único texto, no site da prefeitura, na aba "História de São Leopoldo", demonstrando como age a idealização germânica, através da prefeitura. Essas narrativas, posteriormente, vão chegar ao ensino básico nas escolas do município, causando grandes prejuízos aos alunos negros ou indígenas que não se identificam, nem se veem representados por essas narrações.

Para o ano de 2024, está sendo preparada pela prefeitura, em parceria com instituições, a comemoração do bicentenário da chegada dos germânicos. Essa celebração, segundo consta no site da prefeitura, "[...]reafirma suas origens germânicas, mas também uma cidade aberta à imigração, pluriétnica, moderna e cosmopolita" (SÃO LEOPOLDO, 2021) ${ }^{10}$. Após todas as explicitações feitas em relação aos germânicos, no final, temos uma lembrança à diversidade, como se fosse só para constar mesmo. Uma atitude funcional, semi cumpridora de leis afirmativas, mas sem modificar suas bases históricas.

Como exemplo de positivação do germânico, através do Museu Histórico Visconde de São Leopoldo, vê-se o Projeto "O Milagre do Vale: a epopeia de um povo"11 que leva painéis até escolas com objetivo de "[...] aumentar as pessoas com acesso às informações do museu, da imigração alemã, de como iniciou a cidade e a região. Ampliar o acesso à memória de que somos feitos" (DALL'OLMO, 2016, p. 6). O grande problema, aqui, está na insistência dessa narrativa como "epopeia", hierarquizando, excluindo e invisibilizando

10 SÃO LEOPOLDO, Prefeitura Municipal de São Leopoldo hoje, 2021. Disponível em: http://www.saoleopoldo.rs.gov.br/?titulo=Turismo\&template=conteudo\&categoria=464\&codigoCategori

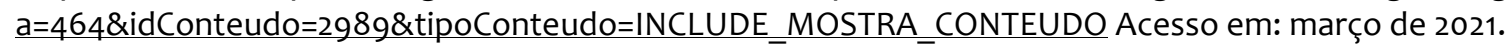

${ }^{11}$ DALL'OLMO, Alecs. Museu Histórico de São Leopoldo na estrada e rumo às escolas. Projeto piloto entrou em prática em instituição no bairro Feitoria. Jornal Vale dos Sinos. 18 de outubro de 2016. Pg. 06. Disponível em: https://www.jornalvs.com.br/_conteudo/2016/10/noticias/regiao/2013229-museu-historicode-sao-leopoldo-na-estrada-e-rumo-as-escolas.h̆tml. Acesso em: março de 2021. 
todas as outras histórias e epistemologias presentes no território, além, ainda, de confundir a história do município com a dos imigrantes, assim como faz a prefeitura municipal.

Os movimentos observados acima, fazem parte de uma série de dispositivos descritos por Basil Bernstein (1996) para a reprodução de certo sistema. No contexto primário tem-se a "produção do discurso", que seria a criação de um “campo intelectual” (BERNSTEIN, 1996, p. 90) a partir da seleção, criação, modificação, transformação de ideias e desenvolvimento, modificação e transformação de discursos especializados. Já o contexto secundário compreende à "reprodução do discurso", fornecendo estrutura ao campo da reprodução seletiva do discurso educacional através de diversos níveis que “regulam a circulação e localização de códigos e suas modalidades” (BERNSTEIN, 1996, p. 90). Assim, o contexto "recontextualizador" seria a realocação do discurso a partir dos dois contextos descritos anteriormente e suas estruturas, "A função da posição, agentes e práticas dentro desse campo e seus subconjuntos é a de regular a circulação de textos entre os contextos primário e secundário" (BERNSTEIN, 1996, p. 91). Essa etapa inclui diversos campos como departamentos especializados; museus, autoridades educacionais locais; sistemas de inspeção; departamentos de Universidades e suas pesquisas; revistas e jornais. Essa é a colonialidade agindo e garantindo a continuidade de suas epistemologias através de interculturalidades funcionais e ou relacionais, que não abalam sua posição privilegiada na produção e reprodução de narrativas.

\section{Repensando a pesquisa como prática política, social e educacional}

O pesquisador, ao cogitar a realização de investigação junto às comunidades indígenas deve, primeiramente, questionar suas motivações para essa pesquisa. Também, deve estar ciente de que não é uma tarefa que possa ser feita do dia para a noite, pois, envolve comprometimento com o conhecimento da comunidade que será partilhado com o investigador, que agirá como um porta-voz desse conhecimento que não lhe pertence. Para isso, é preciso possuir uma relação com a comunidade em questão, e isso, não é questão de um dia, de um e-mail ou de um telefonema. Não é possível ou aceitável, querer pesquisar com uma comunidade, um coletivo de pessoas, sejam indígenas ou não, 
sem a pretensão de envolver-se com a realidade e com as questões caras a essas pessoas, pois, para eles, não se trata de só mais um trabalho acadêmico que renderá um título ao autor, mas, da vida, da história e as vezes até do futuro, deles e de seus filhos.

A ciência, representada pelas pesquisas acadêmicas, deve ser parceira das comunidades e, nesse sentido, ser uma prática política à medida que essas teorias são consultadas pelas esferas de Governo; social à medida que são aplicadas à vida das pessoas e educacional à medida que são reproduzidas como validação da ciência.

No texto Povos Indígenas e Antropologia: novos paradigmas e demandas políticas (2015), a pedagoga e antropóloga Rosani de Fátima Fernandes, Kanhgág natural de Santa Catarina, propõe uma etnologia do antropólogo. Devido à sua história de vida como nativa indígena e atualmente antropóloga, formulou uma antropologia que transita entre o mundo fóg (branco/não indígena) e o indígena. Com uma postura de aprendizado ligado à intervenção, no que as comunidades apontam como objetos sociológicos passíveis de serem trabalhados, têm surgido colaborações com perfis interculturais participativos.

Segundo esta autora (FERNANDES, 2015, p. 331), "[...] o exotismo e o estranhamento que marcavam as primeiras elaborações antropológicas foram aos poucos cedendo espaço às novas metodologias [...]", adicionando ainda que "Muitas destas novas elaborações se devem às percepções sobre o papel político e ético dos antropólogos junto aos povos indígenas, a partir de perspectivas plurais e metodologias de pesquisa participativas que anunciam novas formas de produção etnográfica." (FERNANDES, 2015, p. 337). O pesquisador deve ter consciência de que lhe incidirão cobranças sobre o retorno de seu trabalho e, se não houver, deve provocá-las, além do que, a aproximação e negociação dos seus objetivos podem e devem ser aliadas aos objetivos da comunidade:

As lideranças [...] requerem a participação em todas as etapas da pesquisa, além do "retorno", que pode ser a produção de documentos requisitados pelas comunidades, ou mesmo a participação na intermediação de questões diversas junto aos órgãos governamentais e/ou não governamentais, principalmente no estabelecimento de diálogos com profissionais de outras áreas, tal como acontece na 
elaboração dos laudos antropológicos Nesse sentido, a negociação passou a orientar as relações entre comunidades e antropólogos, que são acionados sempre que necessário, principalmente no assessoramento de questões relacionadas à terra, saúde, educação [...] tais negociações, baseadas em relações de confiança, são definidas a partir de parâmetros específicos elaborados de acordo com o entendimento de cada povo indígena, que "cobra" resultados, participa ativamente das pesquisas, avalia o que é produzido e como é produzido, controlando os resultados, faz críticas e participa da elaboração do trabalho como sujeito ativo do processo (FERNANDES, 2015, p. 333)

O envolvimento do pesquisador com as comunidades e os sujeitos faz nascer uma relação de confiança, que só acontecerá com simetria cultural, de classe e com o envolvimento nas demandas da comunidade. O pesquisador e suas metodologias também são percebidos, pois, estes também são observados pelos sujeitos. Pensando nisso, a tarefa clássica do antropólogo se vira contra ele quando os sujeitos pesquisados atuam observando, estudando e etnografando as repercussões que esses cientistas têm deixado para a comunidade.

O antropólogo, na sua tarefa de observar e estudar o outro, é também "etnografado" nas suas minúcias: na forma de falar, de vestir, de andar, de sentar, de comer, no fato de aceitar ou não os alimentos oferecidos, de participar ou não das atividades para as quais é convidado, situações que vão determinar o estabelecimento, ou não, de relações de confiança com as pessoas da comunidade. Atualmente, como antropóloga em formação e a partir dos referenciais da Pedagogia e do Direito, tenho a possibilidade de estabelecer diálogos interdisciplinares e empreender esforços no sentido de atuar de maneira crítica e politicamente situada tanto nas leituras e elaborações que realizo quanto nas intervenções propositivas na formação de professores indígenas e não indígenas e junto ao movimento indígena. (FERNANDES, 2015, p. 326)

Assim, atitudes descompromissadas não passam desapercebidas das comunidades, como podemos atestar nas palavras do Sr. Nÿgrë, Antônio dos Santos, líder da comunidade Kanhgág em São Leopoldo, ao ser questionado sobre a postura geral dos pesquisadores com quem já teve contato: 
Eu, desde que comecei a nossa luta na cidade grande, no Vale do Taquari, na metropolitana, têm muitos antropólogos que são doutorados que tem tirado proveito dos índios, tirado várias pesquisas, vários trabalhos junto do indígena, usando o índio eu sei disso. Aí, chega um certo tempo abandona o índio, não dá retorno. Isso é um crime, considerado como um crime!! Então, eu cuido muito esse lado. Aqui em Porto Alegre mesmo tem uns quantos doutorados que entraram como alunos, que eu sei, conheço e hoje são doutores!! Tirando informação dos índios, tirando informação dos velhinhos, indo nas aldeias e falando com os pajés e só sugado o que eles têm de história real, de lenda real. E hoje, os velhinhos estão lá perto das cinzas, perto do foguinho, passando fome, passando miséria, e o doutorado lá, num grau tão alto que hoje quebra a volta para passar perto de um índio, então isso me ofende muito. Por isso que Hoje eu tô com uma certa idade e não quero falar do meu sagrado para uma pessoa que eu nem conheço, uma pessoa que amanhã eu possa me arrepender. Nem todas as coisas eu falo, tem as coisas sagradas que eu não posso falar, é difícil tirar de mim. (NŸGRE, 2018, p. 20)

Desse modo, optar por metodologias participativas, de ação e baseadas em ética e escuta é a melhor maneira de estabelecer conexões, fortalecer vínculos, contribuir cientificamente e repensar a pesquisa como prática política, social e educacional de reciprocidade. O histórico sobre o início do emprego da pesquisa ação, segundo David Tripp (2005), é controverso, porém, alguns pesquisadores tiveram maior destaque em diversas épocas. Segundo Tripp, entre os anos de 1940 e 1950, esse método foi aplicado com objetivos de desenvolvimento comunitário com Lewin (1946), para mudança organizacional em 1958 com Lippitt, Watson e Westley e, para o ensino, com Stephen Corey $(1949,1953)$.

A partir dos anos de 1960 e 1970 ganha destaque na América Latina e é utilizada para conscientização política e empoderamento com Paulo Freire (1972, 1982) e ainda para o desenvolvimento agrário com Orlando Fals-Borda (1957, 1975, 1986). Temos também, como grandes expoentes desse método, Michel Thiollent e Carlos Rodrigues Brandão, não mencionados por Tripp. Para Adelina Baldissera (2001), a pesquisa ação foi introduzida no Brasil pelo sociólogo João Bosco Pinto, nos campos da educação e planejamento rural, como incentivo à participação dos camponeses nos processos regionais. 
Atualmente, essa metodologia é associada à atuação de movimentos sociais, processos educacionais de análise e nas diversas áreas de gestão, sendo pouco aproveitada não só na área da sociologia, mas de forma geral em diversas instituições educacionais que desconsideram a prática como parte da ciência e, sim, como resultado dela, cabendo aos intelectuais somente a formulação das teorias para uma possível aplicação por terceiros. Isso os isenta do compromisso e da responsabilidade com uma possível ação com objetivos de transformar a realidade investigada. Sobre esse assunto, Michel Thiollent diz que:

Discordamos de colegas que considerem a pesquisa ação como simples atividade de intervenção social, calcada na visão de atores, que não teria contas a prestar às instancias de pesquisa científica e não precisaria validação ou reconhecimento acadêmico. Seja qual for seu grau de intensidade, a vontade de pesquisar e de transformar situações não significa "fazer agitação" ou "propaganda" a favor de soluções preestabelecidas que, na maioria das vezes, revelam-se ilusórias. Não existe neutralidade na pesquisa social em geral, e tampouco na pesquisa ação, mas isso não significa que tal proposta metodológica deva se confundir com as vontades de tal e qual entidade [...]. (THIOLLEN, 2005, p. 9)

A pesquisa ação, nesse sentido, tem um grande potencial de ação transformadora ligado às pesquisas científicas realizadas no interior das universidades.

A forma de pesquisar a realidade implica a participação da população como agente ativo no conhecimento de sua própria realidade e possibilita a mesma adquirir conhecimentos necessários para resolver problemas e satisfazer necessidades. A pesquisa por ser ação, a própria forma ou maneira de fazer a investigação da realidade gera processo de ação das pessoas envolvidas no projeto. $O$ modo de fazer o estudo, o conhecimento da realidade já é ação; ação de organização, de mobilização, sensibilização e de conscientização. A pesquisa-ação por ser participativa, supõe uma co-implicação no trabalho dos pesquisadores e das pessoas envolvidas no projeto onde se faz intercâmbio, socialização das experiências e conhecimentos teóricos e metodológicos da pesquisa. A pesquisa neste sentido constitui-se em uma forma de democratização 
do saber, produzida pela transferência e partilha de conhecimentos e de tecnologias sociais, [...]. (BALDISSERA, 2001, p. 8)

Ao realizar o trabalho acadêmico de forma que concilie as demandas da academia e as das comunidades, o aprendizado torna-se múltiplo e multiplicador de forma que o enriquecimento será ampliado aos diversos sujeitos implicados nesses processos, seja dentro ou fora da academia.

Assim, admitindo a pesquisa como uma prática política, social e educacional, para a formação contemporânea, seja do antropólogo latino-americano ou de outras disciplinas afins, é necessário encontrar enfoques próprios aos sujeitos e à pesquisa desde o Sul, isto é, não desconsiderando o histórico opressor e espoliador, além dos padrões de colonialidade presentes até hoje nas instituições, inclusive científicas, e estruturas que acabam por diferenciar a população em categorias raciais, étnicas, sociais ou "racionais", sendo os povos originários, no caso específico do continente americano, os mais afetados por esse processo colonialista europeu, iniciado em 1492 e que, até hoje, desqualifica suas cosmologias como ciência, porém as investiga de forma exógena e exótica sem considerar sua responsabilidade como legitimador de tais diferenciações. Os cientistas, detentores da legitimação para falar de algo, devem refletir seu papel social para com os sujeitos envolvidos em suas pesquisas.

Segundo Myriam Jimeno (2004), a antropologia latino-americana possui uma estreita relação entre a produção teórica e o compromisso com as sociedades investigadas, daí sua natureza contestadora e crítica, que pretende não só a pesquisa por si só, mas dar valor social e reconhecimento a essas sociedades tão ignoradas pelas narrativas, além de que, “A compreensão da situação, a seleção dos problemas, a busca de soluções internas, a aprendizagem dos participantes, todas as características qualitativas da pesquisa ação não fogem ao espírito científico." (THIOLLENT, 2005, p. 30).

Teoricamente, avançou-se muito na pesquisa e conhecimento de outros saberes, fazeres e culturas, porém, pouco se avançou com a questão prática do reconhecimento desses saberes e das autorias desses fazeres. É possível realizar um trabalho rigoroso 
metodologicamente, porém, que ultrapasse a simples permissão e conhecimento de uma comunidade sobre o que está sendo realizado para que se torne um trabalho em conjunto, com a participação efetiva dos sujeitos em todas as etapas, principalmente na aplicação. Segundo o sociólogo colombiano Orlando Fals-Borda:

Nuestras herramientas especiales de trabajo han sido y son mayormente los marcos de referencia y las técnicas con las que sucesivas generaciones de científicos han intentado interpretar la realidad. Pero bien sabemos que estas herramientas de trabajo no tienen vida propia, sino que toman el sentido que les demos, con sus respectivos efectos en variados campos de la vida y del conocimiento. De allí que no podamos desconocer el impacto social, político y económico de nuestros trabajos, y que, en consecuencia, debamos saber escoger, para nuestros fines, aquello que sea armónico con nuestra visión de la responsabilidad social. (FALS-BORDA, 2009, p. 253-254)

Desse modo, o fazer científico está associado à ação que representa a responsabilidade política e social. A ação está ligada ao modo de fazer e por isso, a escolha da metodologia é fundamental para se chegar ao resultado esperado com a devida responsabilidade social.

A pesquisa-ação por ser participativa, supõe uma co-implicação no trabalho dos pesquisadores e das pessoas envolvidas no projeto onde se faz intercâmbio, socialização das experiências e conhecimentos teóricos e metodológicos da pesquisa. [...] a pesquisa neste sentido constitui-se em uma forma de democratização do saber, produzida pela transferência e partilha de conhecimentos e de tecnologias sociais[...]. (BALDISSERA, 2001, p. 08)

O histórico colonial de violências e privações imposto às comunidades indígenas da América nunca pode ser desconsiderado ao se pretender uma relação com esses indivíduos. Muito já foi feito, falado e escrito sobre os povos indígenas e muito pouco foram eles próprios que disseram. Muitas concepções teóricas e metodológicas ainda utilizadas por pesquisadores não respeitam a autonomia dos sujeitos e trazem consigo 
pré-concepções acadêmicas hierarquizantes e assistencialistas que não servirão para a construção de uma relação genuína. A ciência, da maneira eurocêntrica que está organizada, em nada tem favorecido as comunidades nativas; pelo contrário, tem sempre dado legitimidade à desqualificação e domínio dos europeus sobre seus territórios.

Os europeus, quando chegam na América, inventam a categoria “índios", homogeneizando toda a diversidade presente no território. Segundo Guillermo Bonfill Batalla, "las poblaciones pre hispánicas ván a ver enmascarada su especificidad histórica y se ván a convertir, dentro del nuevo orden colonial, en un ser plural y uniforme: el indio / los índios" (1972, p. 111). No ano de 1550, na cidade de Valladolid, Espanha, há o debate acadêmico jurídico sobre a humanidade ou não das comunidades indígenas americanas, a fim de legitimar a violência praticada em nome dos reis de Espanha, Portugal e do Papa para fins de catequização e exploração do território.

Com o fim da condição colonial e efetivação das repúblicas americanas pós independências, a situação ameríndia não teve melhoras e continuou sendo tratada com as mesmas concepções evolutivas e eurocêntricas anteriores às independências.

La estructura social de las naciones recién inauguradas conservó, en términos generales, el mismo orden interno instaurado durante los tres siglos anteriores $\mathrm{y}$, en consecuencia, los indios continuaron como una categoría social que denotaba al sector dominado baio formas coloniales, ahora en el seno de países políticamente independientes. (BONFILLBATALLA, 1972, p. 118)

A situação tutelar sobre as comunidades nativas nunca cessou. A maioria delas vive em áreas reservadas para aldeamento, processo imposto pelos brancos no qual as terras pertencem ao Governo, podendo ser confiscadas e reutilizadas para "o interesse da soberania do País" (BRASIL, 1988). No Brasil, o maior órgão de controle da política indigenista, a FUNAI (Fundação Nacional do Índio), nunca foi dirigida por um indígena e segue sendo cabide de empregos para indicados partidários que nenhuma relação têm com os indígenas, no sentido de lutar por suas demandas, uma reclamação muitas vezes repetidas por diversos povos indígenas Brasil afora. Não devemos generalizar a atuação 
do órgão, porém sabe-se do imenso hiato que há entre a autonomia dos indígenas e a atuação da FUNAI.

Para Thiollent (2005, p. 30), “Do ponto de vista científico, a pesquisa ação é uma proposta metodológica e técnica que oferece subsídios para organizar a pesquisa social aplicada sem os excessos da postura convencional ao nível da observação, processamento de dados, experimentação, etc.". Desse modo, a pesquisa ação permite ir além de observações e teorizações solitárias para agir em conjunto, porém, sem desconsiderar as justificativas.

\subsubsection{Conciliando demandas comunitárias}

Através de conversas com os Kanhgág, seus jovens, lideranças e principalmente os professores sobre a Escola do fóg (branco não indígena) e a temática indígena na Escola, o que sobressaiu em suas falas foi a falta da estrutura física para uma escola Kanhgág grande e a dificuldade dos jovens quanto às práticas e ao que era imposto nas Escolas não indígenas, ocasionando desistências e diversos conflitos em seus processos de identidade relacionados à escolarização não indígena.

Nesse sentido, todos são unânimes em dizer que o ideal para os jovens da comunidade Por Fi Ga seria cursar todo o ensino, fundamental e médio em escola própria e não como ocorre atualmente, quando as crianças cursam até o $5^{\circ}$ ano e posteriormente precisam transferir-se para a rede pública, nem sempre preparada para o bilinguismo e culturas próprias.

Para que essa e outras garantias sejam efetivadas para os Kanhgág, falta a estrutura da Escola para abrigar esse currículo. Até o ano de 2016, as aulas na comunidade eram realizadas em escola Estadual própria, com uma sala de aula funcionando em dois turnos, sendo no turno da manhã os alunos de $4^{\circ}$ ao $5^{\circ}$ ano e na tarde $1^{\circ}, 2^{\circ}$ e $3^{\circ}$ anos, porém, após anos de reclamações, o teto cedeu e a estrutura foi demolida no início de 2017. Com isso, as aulas passaram a acontecer no Centro Cultural da comunidade, adaptado para receber os alunos. 
Os problemas educacionais dos jovens começam quando os alunos Kanhgág se deparam com a falta de preparo e conhecimento das escolas que os recebem. Sobre a cultura e o bilinguismo, por exemplo, há relatos ${ }^{12}$ como estes, de dois jovens Kanhgág, a respeito de suas experiências escolares fora da comunidade:

Na semana santa vamos colher marcela para vender, isso é muito bom para a comunidade, mas me magoava muito que colegas e alguns professores falassem sobre o cheiro de marcela que íamos para a escola. Deveria ter mais respeito com os direitos indígenas e também mais atenção e conhecimento da nossa realidade por parte de alguns professores. (Entrevistado 4, 2017)

Às vezes não dava para ouvir a explicação. Numa turma de 42 alunos gritando, eu já não entendia muito bem o português, aí quando pedia outra explicação faltava atenção da professora. (Entrevistado 9, 2017)

Desse modo, o fortalecimento da escola indígena no interior da comunidade é a única situação ideal para os Kanhgág. Foi realizado um acordo para construção de uma escola nova para o ano 2018, porém, nenhuma obra começou até o início de 2021, e não foi por conta da pandemia. Sobre essa questão, Josme, diz o seguinte:

Nos vinte e quatro anos de retorno e retomada (1994-2018) da área na cidade de São Leopoldo, Estado do Rio Grande do Sul no Brasil, muitas pesquisas vêm sendo realizadas em torno da escolarização envolvendo temas e inúmeras observações sobre a forma Kanhgág de dar aula ou a ida de estudantes indígenas para escolas fora da comunidade, porém, nenhuma dessas resolveu o verdadeiro problema escolar Kanhgág que é a falta da estrutura física da escola dentro da comunidade. É importante que o apoio governamental ultrapasse a escrita de Leis e priorize a construção de estruturas físicas adequadas para o desenvolvimento da educação diferenciada que os povos indígenas têm direito conforme diversas Leis, como a LDB (1996), Constituição Federal (1988) e OIT 169(1989). Desde o ano de 2017, quando o antigo prédio da escola foi interditado e demolido por problemas estruturais, a escola de $1^{\circ}$ à $5^{\circ}$ anos funciona em dois turnos no Centro Popular da comunidade Por Fi Ga, que foi reformado para acomodar as duas turmas. A falta de um prédio

\footnotetext{
${ }^{12}$ Relatos colhidos em 30, 31/08 e 04/09/2017 em entrevistas semi estruturadas com 14 jovens Kanhgág com idades entre 18 e 34 anos sobre suas experiências em escolas fora da comunidade Kanhgág. $\mathrm{O}$ anonimato foi acordado com eles por se sentirem mais à vontade para falar, visto que alguns ainda estudam nessas escolas.
} 
adequado para as aulas de todas as séries e utilização de um espaço que deveria ser para o uso de todo o público, acarreta diversos problemas quanto a não ocupação desse espaço para outras atividades dos moradores e impossibilidades de ampliação da educação diferenciada na medida em que não há estrutura para o amplo desenvolvimento das atividades, além de que, com a falta de continuidade dos estudos bilíngues, as crianças Kanhgág que saem de sua escola passam por muitas dificuldades pela falta de conhecimento e adaptação da escola fóg que não sabe os receber, nem compreendem o bilinguismo e os direitos indígenas (FORTES KONHKO, 2018, p. 56)

O que sintetiza, para os Kanhgág, toda a questão e problemática envolvidas na falta de uma estrutura física adequada para desenvolverem seus estudos.

Em janeiro de 2017, em um churrasco na comunidade, em uma conversa sobre a minha proposta de dissertação e nossas percepções sobre as escolas fóg e o modo de ensinar e tratar o indígena, ouvi o seguinte relato de um jovem de 16 anos, estudante da $7^{\circ}$ série de uma escola fóg próxima à comunidade "Eu fui falar com a diretora da escola para que meus parentes e os próximos que precisarem estudar nessas escolas não sofram como eu sofri por causa do preconceito e desconhecimento sobre os indígenas."13

Josme, então, nos conta suas experiências na própria universidade e a vontade que teve de desistir por conta da ignorância de alguns doutores professores fóg que desqualificam os alunos indígenas por conta de sua cultura, desconsiderando completamente o contexto histórico e bilíngue desse sujeito, bem como dos seus direitos. Um exemplo disso foi uma renomada professora da Pedagogia com muitas formações, inclusive no exterior, porém, que não conseguiu se adaptar: "No meu primeiro semestre, a professora me falou que para passar na matéria dela eu ia precisar aprender o português, pois como ela iria avaliar alguém que nem sabia falar?" (Informação verbal) ${ }^{14}$. Desse modo, conversamos sobre as possibilidades de trabalhar em conjunto com a Unisinos, já que era a Universidade em que nós três estávamos inseridos,

\footnotetext{
13 Informação Verbal de um Jovem estudante Kanhgág sobre o preconceito na escola não indígena. Em janeiro de 2017 na comunidade Por FiGa.

${ }^{14}$ Informação Verbal de Josme Konhko Fortes sobre os motivos que o levaram a pensar em desistir do curso de Pedagogia. Em janeiro de 2017 na comunidade Por Fi Ga.
} 
além de estar localizada na cidade de São Leopoldo, em uma distância de oito quilômetros da comunidade Kanhgág.

Era das poucas instituições universitárias da região que não tinha qualquer diálogo com essa comunidade, mesmo possuindo um Núcleo de Estudos Afro Brasileiros e Indígenas (NEABI) estabelecido já há alguns anos, porém com atuação nula junto dessa comunidade, sendo percebido por eles e atestado através dessa fala de Josme em entrevista para uma revista:

Todos os anos, na semana do índio, nós preparamos um evento em que fazemos rituais. As escolas do município vão participar, as universidades como a UFRGS e a Feevale sempre participam, exceto a Unisinos, o que não deixa de ser estranho porque é a universidade onde estou estudando que não foi. Integrantes da minha aldeia sempre vêm fazer palestra aqui [na Unisinos] e pedi para a minha professora para ela liberar a turma para assisti-la e ela não liberou, mas isso é importante porque os meus colegas que não são índios têm que saber sobre a minha cultura. Eu conheço minha cultura porque vivo na minha comunidade, mas quem tem que aprender sobre ela são os outros que não são índios. (FORTES KONHKO, 2017, p. 07)

Desse modo, chegamos a duas conclusões naquele dia. Primeira: a necessidade de a Universidade se aproximar da comunidade, não só por ser grande formadora dos professores das escolas básicas da região, mas também pelo fato de os próprios professores da instituição não terem conhecimento da realidade indígena local. Segunda: os jovens da comunidade estavam sendo atrasados em seus estudos devido às representações, falta de compreensão e conhecimento dos professores fóg (brancos; não indígenas).

Muitos estavam animados e com idade para fazer o Exame Nacional do Ensino Médio (ENEM), porém, não tinham concluído os estudos. No momento, o que precisavam, segundo a comunidade, era de fortalecimento para entrarem na escola fóg e de reforço para se formarem no Ensino Fundamental e Médio, possibilitando a ação em duas frentes: as crianças do $4^{\circ}$ e $5^{\circ}$ ano, alunos de Josme na comunidade que, a partir do 
$6^{\circ}$ ano, passavam a estudar fora por falta de uma estrutura física que possibilitasse a ampliação da escola Kanhgág, e os jovens que gostariam de terminar seus estudos.

Portanto, através dos esforços de alguns alunos, nasceu o Projeto de Educação Popular como uma forma de suprir a demanda educacional dos jovens Kanhgág e de aproximar a comunidade da Universidade, como uma potencializadora da autonomia Kanhgág, na medida em que, através de suas estruturas possam colaborar para as demandas de organização no interior da comunidade quanto à formação de referências indígenas realistas e ao reconhecimento acadêmico dos saberes indígenas.

\subsection{Breve histórico: busca por interculturalidade crítica}

Desde o ano de 2007, a comunidade Kanhgág formou uma ëmã (morada) na cidade de São Leopoldo, porém sua retomada de terras nessa localidade teve início em 1994, quando os Kanhgág começam a retornar formando wãre (acampamentos provisórios). Esses contextos de retomadas contemporâneas e ocupação urbana estão ligados aos direitos promulgados pela Constituição Federal de 1988.

O fenômeno, percebido a partir do final dos anos de 1980, deixou essas populações conhecidas como “índios urbanos" (FREITAS, 2005) e representou a possibilidade de muitos grupos Kanhgág, que viviam em condições ruins nas aldeias grandes situadas no norte do Estado, de buscarem melhores condições de vida, além de autonomia política aos grupos dissidentes.

Para compreender melhor a situação das "aldeias grandes", devemos voltar até o início do século XIX, quando chegam os primeiros imigrantes no estado e o espaço começa a ficar restrito. O início dos anos de 1800 foi marcado por intensos e violentos conflitos entre colonos e os Kanhgág, já que os últimos tinham o hábito de circular, entre wãre (acampamento) e ëmã, pelo vasto território situado entre os estados de São Paulo até o Rio Grande do Sul. A abertura de estradas e picadas dentro dos territórios Kanhgág os força cada vez mais em direção ao norte do estado e acirram as disputas internas entre os grupos. 
Já no ano 1846, dá-se início aos aldeamentos oficiais Kanhgág com o objetivo de imobilizá-los em locais pré-estabelecidos. Desse modo, em 1857 é demarcada a terra indígena de Nonohay (409 km distância de Porto Alegre). Os nãos índios, ao forçarem os Kanhgág a ocuparem todos os mesmos espaços, criam nesses locais sistemas de diferenciações, onde algumas famílias viviam privilegiadas em detrimento de outras que viviam em extrema dificuldade, reflexo dos modos de vida históricos dos Kanhgág, que não viviam juntos antes da chegada dos europeus, porém mantinham o diálogo. Não conseguindo viver imóveis, nem em companhia de desafetos, formam novas comunidades. Segundo Aline Francisco (2006), há relatos jesuítas, de 1879, que contam a existência de oito aldeias independentes mesmo com o intenso esforço de mantê-los em Nonohay.

No ano de 1910 é criado o SPI, Serviço de Proteção aos Índios, que na verdade praticou a tutela e as mais variadas violências sendo substituído pela FUNAI, Fundação Nacional do Índio em 1967. Assim, desde o início do século XIX, os Kanhgág se encontram em estado de exceção, sendo o ano de 1988 um marco histórico pelo reconhecimento das cosmologias indígenas e possibilidade do retorno às terras que antes eram proibidas, a menos que "deixassem" de ser reconhecidos como índios perante a Lei.

Mesmo que este histórico de opressão tenha incidido de forma a inviabilizar os projetos de vida dos Kanhgág, a resistência aos processos de dominação e colonização tem sido em igual intensidade. A educação tradicional Kanhgág está vinculada à prática cotidiana. A escolarização nos moldes fóg foi introduzida pelos Jesuítas nos aldeamentos do início do século XIX, porém, com muitas dificuldades, pois, os Kanhgág resistiram em deixar seus filhos nas escolas preferindo os levar junto para onde iam. Através de relatos de Jesuítas em correspondências e diários dessa época, Aline Francisco (2006) conta sobre as dificuldades que tinham os padres em catequizar os Kanhgág: "As narrativas contam que alguns pais indígenas não deixavam seus filhos frequentar a catequese, isolando-os da influência dos padres" (p. 186). Outro fator apontado foi o fato de os Kanhgág seguidamente deixarem os aldeamentos para procurarem comida na mata ou voltarem para suas áreas antigas. Foi o SPI, em parcerias com a Igreja Luterana e diversas "missões" estrangeiras, que consolidaram o modelo de escola bilíngue visto 
contemporaneamente; porém, na época em que foi introduzido tinha como objetivo facilitar a transição para o idioma português.

Para a comunidade Por Fi Ga, a estrutura educacional, como meio de transmitir a língua de forma oral e escrita, ocorre desde os tempos do acampamento provisório às margens da BR-116, como visto em reportagem publicada em 16 de abril de 2006 pelo Jornal Vale dos Sinos (VS), quando moravam em wãre, no Bairro São Miguel, falando sobre a escola que tinham e o estudo bilíngue, ou seja, a comunidade reestruturou a escola onde há o ensino fundamental regular bilíngue Kanhgág e português até $05^{\circ}$ ano. Isso indica uma preocupação com a formação em Kanhgág e fortalecimento dos indivíduos da comunidade desde os primeiros anos da reocupação dos territórios de São Leopoldo em início dos anos de 1990. Até entrarem na área destinada à Por Fi Ga, no Bairro Feitoria, em 27 de dezembro de $2007^{15}$, enfrentaram diversas dificuldades em sete wãre (acampamento) diferentes, sofrendo todo tipo de preconceito e privação.

Atualmente (2021), vivem na Por Fi Ga cerca de 500 pessoas distribuídas em 65 famílias, falantes dos idiomas Kanhgág e português. Durante esse longo processo histórico, os Kanhgág vêm resistindo e lutando por interculturalidades críticas e decolonialidade, isto é, horizontalidade e reconhecimentos de suas epistemologias, de seus direitos à terra, de seus modos de viver, estudar, falar e ser. Não se trata de inserção na sociedade vigente, mas do direito de viver a sua própria.

\section{Considerações finais}

Ao ser questionado sobre o que estava achando do trabalho, o cacique Sr. Antônio deu o seguinte relato:

Olha, para mim, não quanto eu, mas para eles, mas desde que eu sou cacique a gente junto e esta proposta que vocês trouxeram para dentro da aldeia, para a nossa juventude, isso fez muito bem, incentivou nossos jovens, alguns dos nossos jovens estão interessados, estão interessando mais e nós também estamos dialogando com eles é desta forma que consegue de trabalhar, é dessa forma que consegue alcançar aquilo que

\footnotetext{
15 Informação verbal do Sr. Darcy Fortes em 25 de abril de 2018, às 15h, na comunidade Por Fi Ga.
} 
pensa que sonha. Então, é assim. Aqui na nossa aldeia ja tem passado vários, mas que dá essa contrapartida desse trabalho, desenvolvimento, claro que todas essas coisas não são fáceis, não são de um dia para outro, mas junto, batendo buscando que querendo ou não nós temos ter parceiro, um ajuda o outro, então eu tenho visto muito desenvolvimento com a juventude e ainda a tendência é essa proposta é ir amadurecendo, até eu estou ansioso para participar para mim também só fará muito bem de aprender mais umas coisas que eu tenho que aprender e os jovens muito mais, eu tô feliz com isso, tô mesmo, contente com os trabalhos que vocês começaram aqui a fazer, apesar de que é pouco tempo ainda né, que a gente se conheceu, que vocês começaram na minha liderança, mas eu creio que a gente vai buscar muita coisa boa junto, mas não particularmente para nós, mas para a nossa comunidade de forma geral". (NŸGRE, 2018, p. 44)

Essa pesquisa ação constatou que o trabalho em conjunto da comunidade Kanhgág e da Universidade é possível, desde que, sob perspectivas interculturais críticas em busca da decolonialidade acadêmica, no sentido de abrir-se a novas propostas e epistemologias com novas referências, métodos, ações e, principalmente, envolvimentos com as realidades ora somente observadas.

A função da academia como formadora de novos profissionais de todas as áreas deve estar comprometida na diversificação de suas narrativas e também de seus trabalhadores apostando em outros perfis que de fato trarão outras perspectivas, como os indígenas que têm se tornado mestres e doutores, mas que têm tido poucas oportunidades de exercer a docência com os fóg e ensiná-los sobre suas realidades e métodos. Parece que, para os indígenas, o local de fala só vale na informalidade, para informar os pesquisadores que posteriormente publicarão suas percepções acerca do que acharem mais conveniente deixando, como bem nos disse o Sr. Antônio "[...] os velhinhos estão lá, perto do foguinho, passando fome, passando miséria [...]" (NŸGRE, 2018, p. 20). A colonialidade do poder e do saber faz isso. Como agir?

O pensamento decolonial pode ser entendido como uma ética de vida que nos auxilia a refletir a partir dos pontos de vista plurais da América Latina, nesse caso, dos Kanhgág da comunidade Por Fi Ga. Para a decolonialidade, acadêmica ou não, acontecer, é preciso produzir outro sentido ao processo todo, modificar, não só as teorias que utilizamos, mas, fundamentalmente, nossa maneira de nos relacionar, tanto com a pesquisa, quanto com os sujeitos dessa. Portanto, é preciso dialogar com todos os 
envolvidos, refletir e realizar indagações, principalmente a si mesmos. As comunidades, sejam quais forem, querem trabalhar com os pesquisadores e Universidades? De que forma? Quais suas demandas? E dos seus jovens? E mulheres? E crianças? E idosos? É preciso definir menos, escutar mais e horizontalizar as pesquisas potencializando as ações advindas dessas.

\section{Referências}

BRASIL. Lei Federal $\mathbf{n}^{\circ}$ 12.394, de 4 de março de 2011. Confere ao Município de São Leopoldo, no Estado do Rio Grande do Sul, o título de Berço da Colonização Alemã no Brasil. Disponível em: https://www2.camara.leg.br/legin/fed/lei/2011/lei-12394-4-marco2011-610278-publicacaooriginal-131981-pl.html Acesso em: 01 mar. 2021.

BRASIL. Constituição (1988). Constituição da República Federativa do Brasil: promulgada em 5 de outubro de 1988. Disponível em:

http://www.planalto.gov.br/ccivil_03/constituicao/ConstituicaoCompilado.htm acesso em: 01 mar. De 2021

BALDISSERA, Adelina. Pesquisa-ação: uma metodologia do "conhecer" e do "agir". Sociedade em Debate, Pelotas, p.05-26, ago. 2001.

BERNSTEIN, Basil. A estruturação do discurso pedagógico: classe, códigos e controle. Petrópolis: Ed. Vozes, 1996.

BONFIL-BATALLA, Guillermo. El concepto de indio en América: una categoría colonial. Anales de antropologia, Ciudad de Mexico: Universidade Nacional Autônoma do México (UNAM) v. 9, p.105-124, 1972.

CARDOSO. Dorvalino Refef. Aprendendo com todas as formas de vida do Planeta educação oral e educação escolar Kanhgág. Trabalho de Conclusão do Curso de Pedagogia da Universidade Federal do Rio Grande do Sul, 2014.

DALL'OLMO, Alecs. Museu Histórico de São Leopoldo na estrada e rumo às escolas. Projeto piloto entrou em prática em instituição no bairro Feitoria. Jornal Vale dos Sinos, São Leopoldo, p. 6, 18 out. 2016. Disponível em: https://www.jornalvs.com.br/_conteudo/2016/10/noticias/regiao/2013229-museu-historicode-sao-leopoldo-na-estrada-e-rumo-as-escolas.html. Acesso em: 01 mar. 2021. 
DAMASCENO, Maira. Pesquisa ação e possibilidades de interculturalidade crítica e descolonialidade acadêmica junto à comunidade Kanhgág Por Fi Ga em São

Leopoldo/RS. 2018. Dissertação (Mestrado em Ciências Sociais) - Universidade do Vale do Rio dos Sinos, São Leopoldo, 2018.

DUSSEL, Enrique. Europa, Modernidade e Eurocentrismo. In: LANDER, Edgardo (org.). A colonialidade do saber: eurocentrismo e ciências sociais, perspectivas latino-americanas. Buenos Aires: CLACSO, 2005. p.55-77. Disponível em:

http://biblioteca.clacso.edu.ar/ar/libros/lander/pt/lander.html. Acesso em: 01 mar. 2021

ENGEL, Guido Irineu. Pesquisa-ação. Educar, Curitiba: Editora da UFPR, n. 16, p. 181-191, 2000.

ENTREVISTADO 4. Experiências escolares fora da comunidade Kanhgág Por Fi Ga, São Leopoldo/RS. [Entrevista cedida a]: Maira Damasceno. Entrevistas semi estruturadas, anônimas, cedidas à esse trabalho. São Leopoldo: Unisinos, 30 ago. 2017.

ENTREVISTADO 9. Experiências escolares fora da comunidade Kanhgág Por Fi Ga, São Leopoldo/RS. [Entrevista cedida a]: Maira Damasceno. Entrevistas semi estruturadas, anônimas, cedidas à esse trabalho. São Leopoldo: Unisinos, 30 ago. 2017.

FALS-BORDA, Orlando. Cómo investigar la realidad para transformarla. In: FALS-BORDA, Orlando. Una sociología sentipensante para América Latina: antología. Bogotá: Siglo del Hombre: CLACSO, 2009. p.220/253.

FERNANDES, Rosani de Fátima. Povos indígenas e antropologia: novos paradigmas e demandas políticas. Espaço Ameríndio, Porto Alegre, v. 9, n. 1, p. 322-354, jan./jun. 2015.

FOLLMANN, José Ivo et al. Processos de identidade, relações étnico raciais e relações religiosas. São Leopoldo: Casa Leiria, 2017 (Coleção NEABI; v.4. Refazendo laços e desatando nós). Disponível em: http://repositorio.unisinos.br/neabi/processoidentidade/processos_de identidade/assets/basic-html/page-1.html\# Acesso em: 01 mar. 2021.

FORTES KONHKO, Josme. A força política da indigineidade. [Entrevista cedida a] Ricardo Machado. IHU (online) - Revista do Instituto Humanitas Unisinos, São Leopoldo, Ano 17, n. 507, p. 6-8, 19 jun. 2017. Disponível em: http://www.ihuonline.unisinos.br/artigo/6912-aforca-politica-da-indigineidade. Acesso em: 01 mar. 2021.

FORTES KONHO, Josme. Relatos de experiências e vivências: realidades da educação indígena diferenciada na comunidade kanhgág Por Fi Ga em são Leopoldo/RS. In: COLÓQUIO DISCENTE DE ESTUDOS HISTÓRICOS LATINO AMERICANOS, 3., 2018, São Leopoldo. Resumos [...]. São Leopoldo: Unisinos, 2018. 
FRANCISCO, Aline Ramos. Selvagens e intrusos em seu próprio território: a expropriação do território Jê no sul do Brasil (1808-1875). Dissertação (Mestrado em História) Programa de Pós-graduação em História da Universidade do Vale do Rio dos Sinos, São Leopoldo, 2006.

FREITAS, Ana Elisa de Castro. MrurJykre: a cultura do cipó: territorialidades Kaingang na bacia do Guaíba. 2005. Tese (Doutorado em Antropologia Social) Universidade Federal do Rio Grande do Sul, Porto Alegre, 2005.

GROSFOGUEL. Ramón. A estrutura do conhecimento nas universidades ocidentalizadas: racismo/sexismo epistêmico e os quatro genocídios/epistemicídios do longo século XVI. Revista Sociedade e Estado, Brasília, v. 3, n. 1, jan./abr. 2016.

IBGE. Municípios com as maiores populações indígenas do País, por situação do domicílio: população absoluta (Rio Grande do Sul). [Rio de Janeiro]: IBGE, 2010. Disponível em: https://indigenas.ibge.gov.br/graficos-e-tabelas-2.html. Acesso em: 01 mar. 2021.

JIMENO, Myriam. La vocación crítica latinoamericana de la antropología. Maguaré 18, Bogotá, p. 33-58, 2004.

KROTZ, ESTEBAN. La producción de la antropología en el Sur: características, perspectivas, interrogantes. Alteridades, Iztapalapa: Universidad Autônoma Metropolitana, v. 3, p. 05-11, 1993.

KROTZ, Esteban. La diversificación de la antropología universal a partir de las antropologías del sur. Boletín Antropológico, Mérida: Universidad de los Andes, v. 24, n. 66, p. 7-20, 2006. Disponível em: http://www.redalyc.org/articulo.oa?id=74711380002. Acesso em: 01 mar. 2021.

LANDER, Edgardo (org.). A colonialidade do saber: eurocentrismo e ciências sociais: perspectivas latino-americanas. Buenos Aires: CLACSO, 2005. (Colección Sur Sur).

MONEBHURRUN, Nitish; BALBINO, Michelle Lucas Cardoso; ARAUJO, Fernanda Castelo Branco; PANTOJA, Othon ; BRUNO, Míara Bogo; NÓBREGA, Cândida Dettenborn. A definição jurídica da "comunidade”. Revista de Direito Internacional, Brasília, v. 13, n. 3, p. 443-471, 2016.

NŸGRE, Antônio dos Santos. O que está achando do nosso trabalho na educação popular? In: DAMASCENO, Maira. Pesquisa ação e possibilidades de interculturalidade crítica e descolonialidade acadêmica junto à comunidade Kanhgág (Kaingang) Por Fi Ga em São Leopoldo/RS. 2018. Dissertação (Mestrado em Ciências Sociais) - Universidade do Vale do Rio dos Sinos, São Leopoldo, 2018. 
NŸGRE, Antônio dos Santos. Como o senhor analisa a postura dos pesquisadores que já teve contato? In: DAMASCENO, Maira. Pesquisa ação e possibilidades de interculturalidade crítica e descolonialidade acadêmica junto à comunidade Kanhgág (Kaingang) Por Fi Ga em São Leopoldo/RS. 2018. Dissertação (Mestrado em Ciências Sociais) - Universidade do Vale do Rio dos Sinos, 2018. p. 20.

POLLAK, Michael. Memória e identidade social. Estudos Históricos, Rio de Janeiro, v. 5, n. 10, p. 200-212, 1992. Disponível em:

http://bibliotecadigital.fgv.br/ojs/index.php/reh/article/view/1941 Acesso em: 01 mar. 2021.

QUIJANO, Aníbal. Colonialidad del poder, cultura y conocimiento en América Latina.

Anuario Mariateguiano, Lima: Amauta, v. 9, n. 9, p. 116-142, 1997.

QUIJANO, Anibal. Colonialidade do poder, eurocentrismo e América Latina. In: LANDER, Edgardo (org). A colonialidade do saber: eurocentrismo e ciências sociais: perspectivas latino-americanas. Ciudad Autônoma de Buenos Aires: CLACSO, 2005. P.107-130. (Colección Sur Sur)

RAMOS, Alcida Rita. Mundurucu: mudança social ou falso problema? Brasília: Fundação Universidade de Brasília, 1974.

ROSA, Lilian da. O cultivo do cânhamo no Brasil. In: CONFERÊNCIA INTERNACIONAL DE HISTÓRIA ECONÔMICA, 7.; ENCONTRO DE PÓS-GRADUAÇÃO EM HISTÓRIA ECONÔMICA, 9., 2019, Ribeirão Preto. Anais [...]. Ribeirão Preto: USP: ABPHE, 2019.

SÃO LEOPOLDO. Prefeitura Municipal de São Leopoldo. São Leopoldo hoje, [São Leopoldo], 2021. Disponível em:

http://www.saoleopoldo.rs.gov.br/?titulo=Turismo\&template=conteudo\&categoria $=464 \&$ codigoCategoria $=464 \&$ idConteudo $=2989 \&$ tipoConteudo $=$ INCLUDE_MOSTRA_CONTEUD O. Acesso em: 01 mar. 2021.

SILVA, Tadeu Tomáz da. Identidade e diferença: a perspectiva dos estudos culturais. 11. ed. Petrópolis: Vozes, 2012.

SOUZA, Jessé. Tolice da inteligência brasileira: ou como o país se deixa manipular pela elite. São Paulo: LeYa, 2015.

THIOLLENT, Michel. Metodologia da pesquisa-ação. 17. ed. São Paulo: Cortez, 2005. 132 p.

TRIPP, David. Pesquisa-ação: uma introdução metodológica. Educação e Pesquisa, São Paulo, v. 31, n. 3, p. 443-466, set./dez. 2005.

http://www.scielo.br/pdf/ep/v31n3/aogv31n3.pdf. Acesso em: 01 nov. 2020. 
WALSH, Catherine. Interculturalidad y (de)colonialidad. Perspectivas críticas y políticas: Visão Global, Joaçaba, v. 15, n. 1-2, p. 61-74, jan./dez. 2012. Disponível em: http://editora.unoesc.edu.br/index.php/visaoglobal/article/viewFile/3412/1511. Acesso em: 01 nov. 2020.

Recebido em: 07/12/2020 Aprovado em: 04/04/2021

Universidade do Estado de Santa Catarina - UDESC Centro de Ciências Humanas e da Educação - FAED

PerCursos

Volume 22 - Número 48 - Ano 2021 revistapercursos@gmail.com 